Available online on 15.03.2017 at http://jddtonline.info
Open access to Pharmaceutical and Medical research
noncommercial use, provided the original work is properly cited

Research Article

\title{
FABRICATION AND CHARACTERIZATION OF NON STEROIDAL ANTI- INFLAMMATORY ALGINATE BEADS FOR SUSTAINED RELEASE USING NATURAL POLYMER
}

\author{
Kapoor $D^{1 *}$, Patel $M^{1}$, Vyas RB ${ }^{1}$, Lad $C^{1}$, Gujral $G^{2}$ \\ ${ }^{1}$ Dr. Dayaram Patel Pharmacy College,Sardar baug, Station Road, Bardoli, Dist - Surat, Gujarat, India, Pin-394601 \\ ${ }^{2}$ Research scientist, Alembic Pharmaceuticals Ltd.,Vadodara, Gujarat, India
}

\begin{abstract}
Extended release formulations are becoming more popular day by day for the delivery of non-steroidal anti-inflammatory drugs (NSAIDs) because of their ability to maintain optimal and therapeutically effective drug levels for prolonged duration with the reduction in dosing frequency and side effects associated with NSAIDs. Etodolac is a non-steroidal anti-inflammatory drug. It is an inhibitor of cycloxygenase which belongs to the pyranocarboxylic acid group, which is effective in treating fever, pain, and inflammation in the body, which is degraded in the stomach. In the present study, a suitable particulate system of Etodolac has been developed, by ionotropic gelation method for sustained release that would result in prolonged clinical efficacy, reduced frequency of administration and lesser side effects. Micro beads were fabricated with and without using guar gum as polymer and were characterized for particle size and size distribution analysis, flow properties, loose surface crystal study, entrapment efficiency, swelling ratio, percentage yield and drug content uniformity and in-vitro drug release. It was found that the particle size distribution of both formulations was varied within a narrow size range. Drug leaching $(14.98 \% \pm 0.118)$ was more with presence of guar gum. Entrapment efficiency was retarded with the presence of guar gum. Swelling ratio $(53.49 \pm 1.874)$ advocated that guar gum incorporated microbeads swelled more to behave as a matrix for controlled drug delivery. Establishment of highly viscous dispersion with the incorporation of polymer led to high percentage yield $(49.35 \% \pm 01.230)$. Drug release data was fitted to various kinetic models and indicated that the mechanism was according to peppas model. The study discovered that the microbeads of Etodolac could be efficaciously formulated by ionotropic gelation technique with sustained release characteristics.
\end{abstract}

Keywords: NSAIDs, Alginate beads, cycloxygenase, Ionotropic gelation, Guar gum.

Article Info

Received Feb 13, 2017; Review Completed Feb 25, 2017; Accepted March 13, 2017; Available online March 15, 2017

Cite this article as:

Kapoor D, Patel M, Vyas RB, Lad C, Gujral G, Fabrication and characterization of non steroidal anti-inflammatory alginate beads for sustained release using natural polymer, Journal of Drug Delivery and Therapeutics. 2017; 7(2):77-80.

DOI: http://dx.doi.org/10.22270/jddt.v7i2.1401

*Address for Correspondence

Dr. Devesh Kapoor, Dr. Dayaram Patel Pharmacy College, Sardar baug, Station Road, Bardoli, Dist - Surat, Gujarat, India, Pin394601, E-mail: dev7200@gmail.com, Contact Info - +91-7874223242

\section{INTRODUCTION:}

Numerous techniques were reported previously for preparation of sustained release pharmaceutical formulations such as coating an osmotically active drug core with a semi-permeable membrane, encapsulation of beads, pellets or tablets with different levels and types of diffusion barriers. However use of sophisticated equipment in their formulation, number of critical manufacturing process variables, difficulties in scale-up and use of skilled manpower had limited their routine use in the industry. Gastric emptying of a drug is a complex process that makes in vivo performance of drug delivery systems uncertain; however, the floating or hydro dynamically controlled drug delivery systems namely, floating microspheres, micro beads, and 
microcapsules are useful in overcoming such uncertainty. Micro beads are small, solid and free flowing particulate carriers containing dispersed drug particles either in solution or crystalline form that allows a sustained release or multiple release profiles compared with the monolithic formulations. They release the active ingredients through a double mechanism: diffusion and/or biodegradation of the polymer. The cross-linked microbeads, depending on the biodegradability and biocompatibility, can be administered as long lasting medications. The use of coating substances which can dissolve either in different areas of the gastrointestinal tract (depending on $\mathrm{pH}$ and/or the enzymes present) or after a preset time (depending on the thickness) allows coated microbeads to be used both in a space- and- time focused manner. ${ }^{1}$

Etodolac, 2-(1,8-diethyl-4,9-dihydro-3H-pyrano[3,4-b] indole-1-il)acetic acid is an example of non-steroidal anti-inflammatory drugs (NSAIDs). It is especially beneficial in treatment of chronic conditions of arthritis, osteoarthritis and similar rheumatism diseases. Etodolac is a medicine with a short elimination half-life of $8 \mathrm{~h}$ and low and pH-dependent solubility between $\mathrm{pH} 3$ to 7.Thus in order to maintain the effective plasma levels of the drug, its frequent administration are needed which would in turn lead to NSAID-related side effects on gastro-intestinal (GI) system. Also once-a-day sustained action medications for drug molecules with short halflives typically like Etodolac present formulation problems because of their relatively short residence time into GI tract before elimination. ${ }^{2,3}$

Natural polymers particularly in the form of microspheres, have an important role in the before they will have widespread use in clinical situations. Among these issues are better understanding of the kinetics of drug release; more effective ways to control burst phenomena; greater understanding of drug polymer interactions and their effect on shelf life stability; additional animal studies to determine local tissue response, biodegradation rates, and metabolic rate; and, most importantly, as it relates to cancer chemotherapy, well designed Clinical studies to assess efficacy in relation to current therapies. In the area of drug targeting, there needs to be continuing emphasis on understanding the phagocytes and cell receptors. Gua $r$ gum is a natural nonionic polysaccharide being used as drug carrier for colonic delivery system due to its release retarding property and susceptibility to microbial degradation. Guar gum is derived from the seeds of cyamposis tetragonolobus. Guar gum is hydrophilic in nature, swells in cold water and forming viscous colloidal dispersions or sols. This gelling property retards release of the drug from the dosage form as well as it is susceptible to degradation in the colonic environment. ${ }^{4}$

The present paper pronounces the fabrication of microbeads of Etodolac by ionic gelation with and without guargum as polymer, and studies various pre and pro evaluation parameters to obtain the required release rate of Etodolac microbeads.

\section{MATERIALS:}

Etodolac was a gift sample from creative organics, Hyderabad. Guar gum, Methanol, Sodium alginate, Calcium chloride, and Sodium hydroxide were USP/NF quality and were procured from S.D. Fine Chem ltd, Mumbai, India). All other chemicals used throughout the study were of analytical grade.

\section{METHODS}

\section{Fabrication of etodolac alginate microbeads:}

Alginate microbeads, each containing $200 \mathrm{mg}$ Etodolac were fabricated by Ionotropic gelation method. The symphony of an assortment of formulations of the microbeads with their codes is listed in Table 1. Formulation F2 was prepared with guar gum, while F1 was without maize gum. Active pharmaceutical ingredient Etodalac was added to slurries of $2.5 \% \mathrm{w} / \mathrm{v}$ sodium alginate. Both the slurries were independently dispersed thoroughly using mechanical stirrer for 15 minutes and taken in $10 \mathrm{ml}$ hypodermic needle fitted with a 20 gauge needle. The mixtures were added drop wise to calcium chloride solution $(3 \% \mathrm{w} / \mathrm{v})$, and stirred at $200 \mathrm{rpm}$. The gelation time of 1 hour was allowed to complete the curing reaction and to fabricate spherical and rigid microbeads. The beads were unruffled by decantation, washed 3 times with distilled water and dried at $60^{\circ} \mathrm{C}$ for 2 hours in a hot air oven. ${ }^{5}$

Table 1: Fabrication of etodolac alginate microbeads:

\begin{tabular}{|l|l|l|l|l|l|}
\hline $\begin{array}{l}\text { Formulation } \\
\text { code }\end{array}$ & $\begin{array}{l}\text { API } \\
(\mathbf{m g})\end{array}$ & $\begin{array}{l}\text { Sodium alginate } \\
(\boldsymbol{\%} \mathbf{w} / \mathbf{v})\end{array}$ & $\begin{array}{l}\text { Calcium chloride } \\
(\boldsymbol{\%} \mathbf{w} / \mathbf{v})\end{array}$ & $\begin{array}{l}\text { Maize starch } \\
(\mathbf{m g})\end{array}$ & $\begin{array}{l}\text { Curing time } \\
(\mathbf{m i n})\end{array}$ \\
\hline F1 & 200 & 2.7 & 5 & NIL & 25 \\
\hline F2 & 200 & 2.7 & 5 & 200 & 25 \\
\hline
\end{tabular}

\section{Characterization of etodolac alginate microbeads:}

\section{Physical characterisation:}

The particle sizes of the microbeads were determined using optical microscopy method. The microbeads were mounted in light liquid paraffin and the diameters of 100 particles were measured by means of an optical microscope with calibrated micrometers and the mean diameter was calculated. ${ }^{6}$

\section{Size determination of microbeads:}

Particle size was determined by using a laser diffraction particle size analyzer [Cilas 1064L, Orleans, France]. Microbeads were suspended in the chamber of the particle size analyzer containing distilled water, and the particle size was determined using the software provided by the manufacturer. ${ }^{6}$ 


\section{Drug entrapment efficiency:}

It is the quantity of the drug retained by the system. There are two types of methods to calculate this, one is direct method and other is indirect. Here the direct method was used to calculate the entrapment efficiency. The calculated amount of the microbeads were crushed and digested with acetone for 2 hours with continuously shaking. The solution was stirred on a magnetic stirrer for $15 \mathrm{~min}$, filtered and $1 \mathrm{ml}$ of the filtrate was diluted using phosphate buffer ( $\mathrm{pH}$ 6.8) and analysed spectrophotometrically at $274 \mathrm{~nm}$. The drug entrapment efficiency was calculated as per the following formula. ${ }^{7}$ The $\%$ entrapped drug was calculated by using following formula:

$\%$ entrapped drug $=$ Total amount of drug found in formulation/ Total amount of drug used in formulation $\times$ 100

\section{Swelling ratio:}

Swelling properties of the drug loaded microbeads were determined at $\mathrm{pH}$ range 6.8 . Thirty dried beads were placed in phosphate buffer $(\mathrm{pH}$ 6.8) and allowed to swell at $37^{\circ} \mathrm{C}$. After 2 hour interval, the equilibrium swollen beads were observed and measured by optical microscopy. Swelling ratio was determined from the following relation: ${ }^{8}$

Swelling ratio $=($ Mean diameter at time $\mathrm{t}$ - initial diameter)/Initial diameter of beads $\times 100$

$\%$ yield:

The percentage yield of micro beads has been calculated using following equation. ${ }^{9}$
Percentage yield of microbeads $=$ Total yield of microbeads/Total weight of polymer $\times 100$

\section{In-vitro drug release:}

The in-vitro drug release behavior of the microbeads was evaluated in phosphate buffer $(\mathrm{pH} \mathrm{6.8)}$. The basket method was used to carry out the dissolution tests. The basket position was set at $2.5 \mathrm{~cm}$ from the bottom of the flask and speed was adjusted to $75 \mathrm{rpm}$. The dissolution studies were carried out in $900 \mathrm{ml}$ phosphate buffer maintained at $37 \pm 0.5^{\circ} \mathrm{C}$. Microbeads containing 200 $\mathrm{mg}$ of the drug were employed in each case. Aliquots of $5 \mathrm{ml}$ were withdrawn and immediately replaced the dissolution medium to preserve a constant volume of $900 \mathrm{ml}$. Stirring was continued for 6 hours and speed was increased to $250 \mathrm{rpm}$ for the last 20 minutes in order to estimate the $100 \%$ release point. The samples were filtered and absorbance was determined at $274 \mathrm{~nm}$ using UV-Visible spectrophotometer against an appropriate buffer as a blank. ${ }^{10}$

\section{RESULTS AND DISCUSSION}

\section{Particle size and size distribution analysis:}

It was established that the particle size distribution of both formulations was varied within a narrow size range as shown in Table 2. But the mean particle sizes were dissimilar among these formulations. The outcome indicated that the proportional boost in the mean particle size of microbeads augmented with the existence of guar gum in the formulation. This could be certified to the formation of large droplets during addition of polymer solution to the gelling agent.

Table 2: Average mean diameter of the etodoloac alginate beads

\begin{tabular}{|l|l|l|}
\hline Contents & F1 & F2 \\
\hline Surface mean diameter $(\mu \mathrm{m})$ & $415.48 \pm 0.122$ & $438.71 \pm 0.208$ \\
\hline Volumer mean diameter & $414.44 \pm 2.33$ & $424.90 \pm 0.22$ \\
\hline Surface length mean diameter & $417.28 \pm 2.56$ & $428.45 \pm 3.21$ \\
\hline Volume surface mean diameter & $424.76 \pm 8.77$ & $435.56 \pm 1.87$ \\
\hline Weight moment mean diameter & $430.11 \pm 1.23$ & $434.98 \pm 0.99$ \\
\hline
\end{tabular}

\section{Entrapment efficiency:}

The amount of drug entrapped was more in F1 (38.11\% $\pm 0.11)$ that does not contain guar gum when compared to F2 $(24.55 \% \pm 1.241)$. This may be attributed to lesser number of binding sites of alginate for $\mathrm{Ca}^{+}$ions resulting in the formulation of a less dense gel membrane which, in turn, increases influx of $\mathrm{Ca}^{+}{ }^{+}$ions leading to diminish in drug entrapment efficiency.

\section{Flow properties:}

The results presented in Table 3 showed that F2 which has the polymer incorporated is more freely flowing than F1 which be deficient in polymer. Thus, the microbeads if tabletted or encapsulated, requires fewer amount of lubricants and ensures small production cost leading to its practicability for large scale production.
Table 3: Values for different flow properties parameters for $\mathrm{F} 1$ and $\mathrm{F} 2$

\begin{tabular}{|l|l|l|}
\hline Properties & F1 & F2 \\
\hline Angle of repose & $25.78^{\circ} \pm 2.33$ & $29.11^{\circ} \pm 1.87$ \\
\hline Bulk density & $0.42 \pm 3.456$ & $0.48 \pm 1.987$ \\
\hline Tapped density & $0.55 \pm 4.21$ & $0.48 \pm 0.256$ \\
\hline Carr's index & $22.45 \pm 1.89$ & $9.78 \pm 2.22$ \\
\hline Hausners's ratio & $1.29 \pm 0.99$ & $1.10 \pm 2.45$ \\
\hline
\end{tabular}

\section{Swelling ratio and percentage yield of microbeads:}

The mean diameter of swelling beads to dried beads was found to be greater for formulation prepared by utilizing maize starch polymer F2 $(53.49 \pm 1.874)$, compared to F1 (55.27 \pm 0.139$)$ suggesting that guar gum microbeads may begin to puff up more and act as matrices for controlled release of incorporated drug. The percentage yield was found to be elevated for the formulation 
equipped using guar gum polymer F2 $(49.35 \% \pm 01.230)$ when compared to F1 $(43.17 \pm 1.132 \%)$. This could be due to the configuration of elevated viscous polymer dispersion which is not lost during manufacturing process.

\section{In-vitro drug release:}

The drug release kinetics is presented in Table 4 and follows a complex order drug release. The correlation co-efficient $(\mathrm{r} 2$ value $=0.966)$ indicates that the release mechanism is diffusion and the $\mathrm{n}$ value of Peppas model (0.339) indicates that the mechanism of drug release follows Fickian diffusion. This suggests that drug release occurs mainly by diffusion through polymer matrix from a region of high concentration to lower concentration.

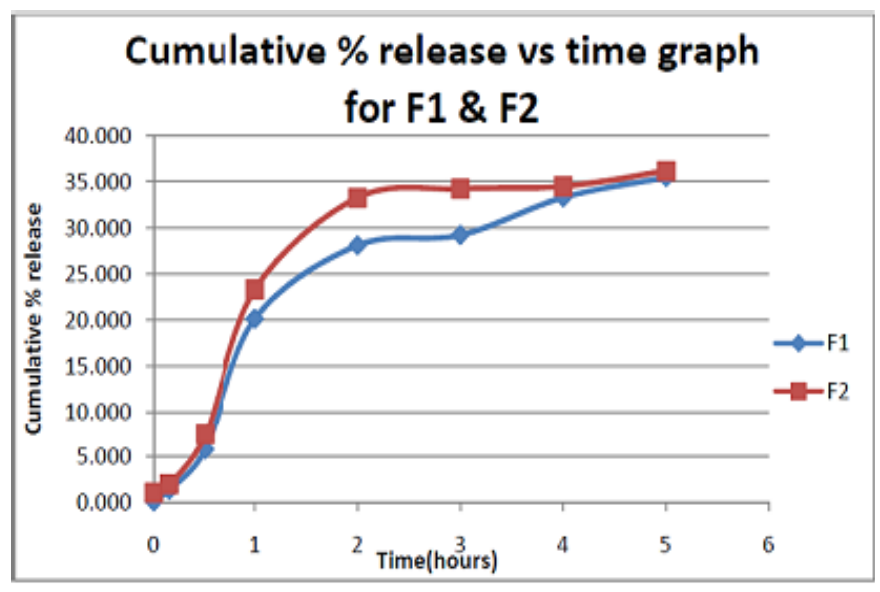

Figure 1: CPR versus time graph for both the formulations

Table 4: In-vitro release kinetic models

\begin{tabular}{|l|l|l|l|l|}
\hline \multirow{2}{*}{ Fabrication code } & \multicolumn{4}{l|}{ Correlation coefficient $\left(\mathbf{r}^{2}\right.$ value $)$} \\
\cline { 2 - 5 } & Zero order & First order & Higuchi model & Peppas model \\
\hline F1 & 0.841 & 0.696 & 0.876 & 0.821 \\
\hline F2 & 0.971 & 0.718 & 0.982 & 0.962 \\
\hline
\end{tabular}

\section{CONCLUSION:}

The current study exposed that ionotropic gelation technique can be effectively used for fabrication of Etodolac microbeads. Assortment of polymer is important to attain extra entrapment efficiency and to sustain the release of drug from beads. Guar gum blended microbeads showed more entrapment efficiency

\section{REFERENCES:}

1. Ganesh N S, Bharathi G, Joshi H, Jayanthi C, Singh DP. Buoyant multiparticulate drug delivery a focus on hydrogel beads. World J Pharm Pharm Sci. 2013; 2: 450-464.

2. Benet LZ. Rheumatol, Pharmacokinetics of sustained release Etodolac. Int J Pharm., 1993; 13(2):S3-5.

3. Raghuvanshi RS, Rampal A, Sen H. Extended release formulation of Etodolac. US Patent, US6586005, 2003.

4. Chourasia MK, Jain SK.

Pharmaceutical approaches to colon targeted drug delivery sy stem. J. Pharm. Pharmaceutical Sci. 2003; 6(1):33-66

5. Alfred Martin. Physical pharmacy. 6th ed. Lippincott Williams and Wilkins, Inc: Philadelphia, 2011.

6. Yellanki SK, Nerella NK. Stomach specific drug delivery of riboflavin using floating alginate beads. Int J Pharm Pharm Sci. 2010; 2:21-25.

7. Yurdasiper A, Sevgi F. An overview of modified release chitosan, alginate and eudragit RS microparticles. J Chem Pharm Res. 2010: 2:704-721. as well as more sustained release of drug. Also the formulation containing guar gum was found to be freer flowing. Therefore guar gum is moderately improved polymer of choice for Etodolac when compared to a formulation without guar gum. Guar gum can also be used for texture and clarity and also as a binder and excipient.

8. Lachman L, Herbert A, Lieber mann, Kanig JL. The theory and practice of industrial pharmacy. 3rd ed. Lea and febriger, Inc: Philadelphia, 2008.

9. Vyas SP, Khar RK. Targeted and controlled drug delivery novel carrier systems. Edn 1, CBS publishers and distributors, New Delhi, 2006; 417-457.

10. Malviya S, Singh S, Pandey J, Avinash K. Kondalkar, Tagde P. Formulation and evaluation of floating microbeads of ciprofloxacin Hydrochloride by emulsion gelation method. Der Pharmacia Lettre 2013; 5:63-68.

11. Radhika PR, Sunkara M, Sivakumar T. Masking Bitter Taste of Ciprofloxacin by Microbeads Using Hydrophilic Polymer. J Adv Sci Res. 2012; 3:64-66.

12. Badarinath AV, Reddy RK, Rao KM, Alagusundaram M, Gnanaprakash K. Formulation and characterization of alginate microbeads of flurbiprofen by ionotropic gelation technique. Int J Chem Tech Research. 2010; 2:361-367. 